\title{
APLICAÇÃO DO CONCEITO DE COMPETÊNCIAS À ATUAÇÃO DO PIANISTA DE CORO
}

\author{
Application of the Competences Concept to \\ the Choir Pianist Actuation
}

\author{
Aplicación del concepto de competencias a \\ la actuación del pianista del coro
}

\author{
RAFAEL RICARDO FRIESEN \\ Universidade Federal de Roraima \\ rafael.friesen@ufrr.br
}

\author{
Maria Bernardete Castelan Póvoas \\ Universidade do Estado de Santa Catarina \\ bernardetecastelan@gmail.com
}

Resumo: Neste artigo é apresentada uma discussão sobre o conceito de competência e resultados de survey, originados da dissertação de mestrado de Friesen. Tendo como base teórica os autores Boterf, Perrenoud e Zarifian, prevê a aplicação do conceito em questão e da argumentação adentrada à atuação do pianista de coro. As competências de pianistas colaboradores de coros no Brasil foram extraídas de dados obtidos por meio de survey nacional e mensuradas em escala Likert. Verificou-se que é possivel aplicar o conceito em questão à função do profissional em foco, a qual requer o domínio de diversas competências específicas. Como implicação da prática e do emprego de ações correlatas, existe a possibilidade de que informações levantadas venham a ser utilizadas na formação de pianistas colaboradores, especialmente para atuação com coros brasileiros, e não somente considerando uma orientação voltada a este mercado de trabalho específico.

Palavras-chave: Colaboração pianística. Coro. Competências.

Abstract: This paper aims to present a discussion about the concept of skill based on the authors Boterf, Perrenoud and Zarifian, applying and exemplifying the concept to the performance of the choir pianist. The skills of collaborating choir pianists in Brazil were previously defined in an earlier Friesen study. It has been found that it is possible to apply the concept of skill and that function requires the pianist to master several specific skills. It was concluded that the application of this concept can be included in the training of pianists, especially in the accompaniment of Brazilian choirs, considering a career guidance for the specific job market.

Keywords: Collaborative Piano. Choir. Skills.

Resumen: Este artículo presenta una discusión sobre el concepto de competencia y los resultados de la encuesta, que se originaron a partir de la tesis de maestría de Friesen. Teniendo como base teórica los autores Boterf, Perrenoud y Zarifian, prevé la aplicación del concepto en cuestión y los argumentos adentrados a la acción del pianista de coro. Las competencias de pianistas colaboradores de coros en Brasil fueron extraídas a partir de datos obtenidos mediante encuesta nacional y medidos en escala Likert. Se descubrió que es posible aplicar el concepto en cuestión a la función del profesional en enfoque, que requiere el dominio de varias habilidades específicas. Como consecuencias de prácticas y acciones que se relacionan, existe la posibilidad de que las informaciones recopiladas se utilizen en la formación de pianistas colaboradores, especialmente para trabajar con coros brasileños, y no sólo, considerando una directriz dirigida a este mercado de trabajo específico.

Palabras clave: Colaboración pianística. Coro. Competencias. 


\section{INTRODUÇÃO}

Ao abordarem sobre competências requeridas ao músico profissional no desempenho da colaboração pianística, diversos autores fazem uso dos termos competência e habilidade indistintamente, como notado por Cianbroni (2016, p. 22). Mas seriam termos sinônimos ou com significados e usos diferentes? Assim, propõe-se, aqui, apresentar uma discussão sobre o conceito de competência a partir de Zarifian (2001), Perrenoud (1999) e Boterf (2003), objetivando-se aplicar tal conceito e argumentações levantadas especificamente à atuação do pianista de coro. As competências específicas deste instrumentista foram levantadas a partir de Friesen (2018), que realizou um survey nacional sobre a temática, em pesquisa.

Para que um profissional esteja capacitado ao mercado de trabalho é preciso suprir "uma combinação singular de competências" (Boterf, 2003, p.13), pois o profissionalismo supõe tal combinação. Assim, tendo em vista o valor do conceito de competência, inclusive na sua busca de substituição do modelo de gestão taylorista ${ }^{1}$, justifica-se uma discussão em torno do conceito em questão e da sua aplicação na área da colaboração pianística, com possivel expansão para outras áreas. Tal expansão já ocorre em alguns campos, como no caso da educação, por meio do trabalho de autores como Perrenoud (2000).

\section{Metodologia}

A pesquisa aqui apresentada resulta de dissertação que visou levantar e discutir as competências de pianistas de coro no Brasil, tendo sido realizado um survey nacional com 134 pianistas e regentes (Friesen, 2018, p.51). Os sujeitos responderam a um questionário que serviu como ferramenta para a coleta dos dados. Do total de respondentes, 34 são pianistas, 51 são regentes e 49 são regentes-pianistas ${ }^{2}$, de todas as regiões do país, muito embora tenha havido mais respostas do Sul e do Sudeste (Friesen, 2018, p.58). Tem-se, também, que a maioria atuava com coros amadores e/ou religiosos (Friesen, 2018, p.53) há mais de cinco anos (Friesen, 2018, p.57) e com formação em nível de Pós-Graduação em Música (Friesen, 2018, p.61). As competências específicas inerentes ao pianista de coro foram mensuradas em escala Likert, de acordo com a percepção de cada respondente. Os cinco níveis de intensidade de demanda das

\footnotetext{
${ }^{1}$ O modelo de administração do engenheiro Frederick Taylor é chamado de taylorismo e consiste em controlar todas as etapas do processo. Estão associadas a este modelo as linhas de produção, e, graças a tal sistema gestor, "a produtividade das empresas americanas teve um aumento vertiginoso" (Rosa, 2011, p.24). Aplicamse os seguintes princípios: divisão do trabalho, identificação da forma mais eficiente de realização do trabalho, seleção do indivíduo certo para determinada tarefa, treinamento do trabalhador e fiscalização do trabalho.

${ }^{2}$ Este termo foi criado por Friesen (2018) para definir aqueles sujeitos que atuaram tanto na regência quanto na execução pianística, comumente de forma simultânea.
} 
competências elencadas foram: desnecessário, pouco necessário, razoavelmente necessário, muito necessário e imprescindivel.

A partir dos dados obtidos, realizou-se cruzamentos de informações entre as respostas sobre as competências em si e as demais informações obtidas sobre os sujeitos. Averiguou-se, por exemplo, em quais categorias de coros os respondentes atuaram e como seu tempo de atuação pode ter influenciado nas suas percepções quanto à intensidade da demanda de determinada competência específica; qual o nivel de formação de acordo com a região de atuação; como a forma de atuação (como pianista, regente e/ou regente-pianista) pode ter afetado as respostas, entre outros cruzamentos considerados importantes a partir de hipóteses surgidas ao longo da pesquisa (Friesen, 2018).

\section{O CONCEITO DE COMPETÊNCIA E SUA APLICAÇÃO À FUNÇÃO DE PIANISTA DE CORO}

Conceitos de competência e profissionalismo surgiram devido ao problema vivenciado por empresas que perderam, com seus trabalhadores, o know-how necessário (Boterf, 2003, p. 16). Para o autor, "competência é um sistema, uma organização estruturada que associa de modo combinatório diversos elementos" (Boterf, 2003, p .61).

Surge, então, a proposta de modificação de mentalidade na avaliação e gerenciamento da mão de obra, migrando de um sistema onde o maior valor estava nas capacidades físicas do trabalhador para outro onde é preciso "entendimento do processo de trabalho" (Zarifian, 2001, p. 14). De certa forma é como se se passasse a solicitar o cérebro ao invés do corpo. Em tal contexto, é preciso entender os problemas do desempenho e ter capacidade de iniciativa, enquanto que, na fundamentação taylorista de linha de produção, que se pretendeu substituir, o trabalhador tende a ser pouco mais que um executor de tarefas. Não que a atribuição de tarefas deixe de existir, ou que se substitua o corpo pelo intelecto "(como é possivel mobilizar seu corpo sem mobilizar seu cérebro?)” (Zarifian, 2001, p. 22), mas precisase de mais do que uma mera atuação automatizada no local de trabalho.

À época da elaboração do conceito de competência, tal automatização expandia-se à área industrial, realidade que, somada à difusão da informática, deu início à substituição e melhoria de diversas atividades do trabalhador humano, inclusive ampliando o fluxo de produção. Tais razões, entre outras, criaram a necessidade de reposicionamento da atividade humana e, de acordo com Zarifian, "ela se reposiciona no confronto com eventos" (2001, p. 41). Tal autor define eventos como acontecimentos inesperados, parcialmente imprevistos, que perturbam o sistema de produção no seu desenrolar. Em uma oficina de produção eles seriam "as panes, os desvios de qualidade, os materiais que faltam, as mudanças imprevistas na programação da fabricação, uma encomenda repentina de 
um cliente etc. Em resumo, tudo o que chamamos de acaso" (Zarifian, 2001, p. 41). No caso do pianista de coro, seriam, por exemplo, situações como a impossibilidade de o regente estar no ensaio, um naipe deixar de cantar sua parte ou repentinamente desafinar, entre outras circunstâncias imprevisiveis.

Sobre a relação entre o trabalhador e os eventos surgidos, é preciso compreender o que se espera de um profissional competente: que seja capaz de "produzir um número infinito de ações não-programadas" (Perrenoud, 1999, p. 20). Semelhantemente, vê-se também em Boterf (2003, p. 20) que "as empresas e as organizações devem dispor de homens e mulheres capazes de enfrentar o inédito e a mudança permanente". Em uma organização "centrada na qualidade total a serviço do cliente, as competências não podem se limitar à aplicação de instruções: a iniciativa e a responsabilidade são requeridas e caracterizam as novas exigências profissionais" (Boterf, 2003, p. 31). Usando os exemplos anteriores, caberia ao pianista de coro substituir o regente na sua ausência, auxiliar o naipe inseguro tocando sua parte como reforço, ter desenvolvido sua leitura à primeira vista, a ponto de não ser pego desprevenido etc.

A partir do remanejamento do trabalhador para uma atividade menos automatizada adota-se a premissa de que trabalhar passa a ser estar atento às possibilidades de imprevistos, bem como seu enfrentamento e resolução, objetivando-se a restauração da normalidade. Assim, a atuação profissional ocorre antes do evento, pela atenção aos incidentes que podem surgir durante o evento, através de interferência pertinente e ativa (muitas vezes sob pressão), e após o evento, através de ponderação sobre o ocorrido, de forma a evitar sua reaparição indesejada (Zarifian, 2001, p. 41; Boterf, 2003, p. 39 e 40).

A partir das exposições apresentadas, entende-se que o trabalho passa a ser visto como "a ação competente do individuo diante de uma situação" (Zarifian, 2001, p. 42), considerando-se que diversas situações não programadas e singulares fazem parte das ocupações laborais. Em alguns contextos de trabalho, as tarefas precisam ser descritas, mas sem uma limitação muito intensa, a fim de o trabalhador poder apresentar seus próprios resultados, pois estes valem mais do que os procedimentos (Boterf, 2003, p. 27). Isso pode ocorrer na atuação com coros, considerando-se que as abordagens na preparação de um repertório são muitas, mas é o resultado sonoro que tem mais valor.

Tais mudanças de paradigmas também alteram a percepção de experiência, pois não é mais a quantidade de tempo atuando em um posto de trabalho que a forma, mas é através da variedade de eventos enfrentados e da qualidade da organização que se pode afirmar que um profissional é experiente (Zarifian, 2001, p. 44). Claro que, quanto mais tempo atuando em uma função, maior a chance de se vivenciar múltiplos imprevistos, o que facilita o processo de aprendizado dos sujeitos. 
Sobre competência individual, Zarifian sustenta que esta "não é nada sem o conjunto de aprendizagens sociais e de comunicações que a nutrem de todos os lados" (2001, p. 56). Com alguma semelhança, Perrenoud (1999, p. 21) sustenta que "as competências, no sentido que será aqui utilizado, são aquisições, aprendizados construídos, e não virtualidades da espécie”, e ainda que "a competência constrói-se com a prática [...], na qual se multiplicam as situações de interação".

Percebe-se que existem elementos sociais fundamentais para a construção de competências e que tais elementos estão impregnados na formação do indivíduo. Da mesma forma, a coletividade característica da música coral influencia na preparação e no resultado do trabalho musical. Some-se a isso a complexidade da música coral, que requer a mobilização de redes de comunicação, pois se não houver troca constante de informações no grupo a música dificilmente acontece adequadamente. Sobre a questão da socialização no trabalho, Zarifian (2001, p. 58) expõe que

[...] em síntese, pode-se dizer que sob múltiplas formas trabalhar torna-se simultaneamente: a aplicação concreta de uma competência individual, possuída e desenvolvida como propriedade particular por uma pessoa; a inserção em processos de socialização que permitem inclusões sociais e profissionais; a colocação de um conjunto de competências individuais em comunicação e em situação de colaboração conjunta, em uma atividade cooperativa.

Abordando a forma de organizar o trabalho, encontra-se em Zarifian uma proposta de "uma organização celular em rede, animada por projetos" (2001, p. 63). Essa orientação de um grupo pequeno, com certa autonomia e voltado para um objetivo comum (Zarifian, 2001, p. 59), encontra equivalente no Núcleo Coral proposto por Paiva (2006), que é formado por pianista, regente e coro. Neste caso, regente e pianista atuam orientando o coro e avaliando mutuamente suas atuações em rede, objetivando uma boa prática musical.

Em tal proposta de organização, a competência é assumida por um coletivo, depende de cada individuo e visa um objetivo comum, como no conceito de competência coletiva defendido por Boterf (2003, p. 229). Nessa visão, o pianista necessita atuar corretamente para cumprir com o papel que lhe cabe, através de atitudes equilibradas e uso engenhoso dos recursos disponíveis, sem descartar a possibilidade de experimentação (Boterf, 2003, p. 28).

Sobre a definição do conceito de competência, Zarifian apresenta três definições complementares, defendendo que por meio delas é possivel a apreensão e a mobilização consciente de tal conceito (2001, p. 76): a) "Competência é 'o tomar iniciativa' e 'o assumir responsabilidade' do individuo diante de situações profissionais com as quais se depara" (Zarifian, 2001, p. 68); b) "é um entendimento prático de situações que se 
apoia em conhecimentos adquiridos e os transforma na medida em que aumenta a diversidade das situações" (Zarifian, 2001, p. 72); c) "é a faculdade de mobilizar redes de atores em torno das mesmas situações, é a faculdade de fazer com que esses atores compartilhem as implicações de suas ações, é fazê-los assumir áreas de corresponsabilidade" (Zarifian, 2001, p. 74).

As expressões tomar iniciativa e assumir responsabilidade significam que o profissional precisa cumprir os procedimentos que lhe cabem, ou seja, a partir do "repertório de normas de ação, escolher a mais adequada" (Zarifian, 2001, p. 69). "A responsabilidade supõe o profissionalismo" (Boterf, 2003, p. 32). Transpor tais informações para o pianista de coro significa dizer nada mais que o óbvio: ele deve cumprir com o que é de sua alçada. É preciso saber, por exemplo, se é necessário deixar a parte de acompanhamento pianístico momentaneamente para auxiliar algum naipe através da execução de sua linha, e isso sem que tal ação seja requisitada pelo regente. Assumir responsabilidade significa que o pianista tem consciência de seu papel de colaborador e coparticipa da condução do coro, inclusive através de sua execução instrumental.

Sobre o entendimento prático, cabe dizer que a dimensão cognitiva não é suficiente, é preciso traduzi-la em praxis. A esse respeito Zarifian (2001, p. 72) diz que "não se trata de empregar um conhecimento prévio, mas de saber mobilizá-lo judiciosamente em função da situação". Ao pianista não basta saber que é preciso um campo de visão mais amplo para realizar a leitura de uma partitura em forma de "grade", tal habilidade precisa ser posta em prática quando for requisitada. Manifesta-se ainda o autor: "não há exercício da competência sem um lastro de conhecimentos que poderão ser mobilizados em situação de trabalho" (Zarifian, 2001, p. 72).

Consideremos a equivalência entre conhecimento e habilidade, dada a percepção de que "música é algo essencialmente prático e que o termo conhecimento corre o risco de carregar alguma conotação mais teórica" (Friesen, 2018, p. 44). Em certo sentido, Perrenoud também aponta nessa direção ao sustentar que habilidade "é uma 'inteligência capitalizada', uma sequência de modos operatórios, de analogias, de intuições, de induções, de deduções, de transposições dominadas, de funcionamentos heurísticos rotinizados" (1999, p. 30). Assim, o pianista de coro para ser bem-sucedido precisa ter desenvolvido um rol de conhecimentos e habilidades a serem utilizados e transformados de acordo com as demandas.

A capacidade de mobilização de redes de atores em torno de um objetivo comum é considerada característica necessária quando "qualquer situação um pouco mais complexa excede as competências de um único individuo" (Zarifian, 2001, p. 74), como visto também em Boterf: "O profissional não pode mais ser competente sozinho e de maneira isolada" (2003, p. 127). A proximidade entre tais redes de atores e a prática coral é evidente, pois é preciso que cantores, regente e pianista atuem 
conjuntamente para atingir o resultado. Note-se que, embora o piano permita a execução de reduções, é óbvio que não se obtém o mesmo resultado das vozes por questões como o timbre, por exemplo. Assim, naquilo que lhe diz respeito e colaborando com o regente, o pianista de coro precisa mobilizar atores como os cantores, o instrumento etc, sempre objetivando a prática musical.

Conclui-se que atuar competentemente significa assumir responsabilidades no âmbito em questão, mobilizando conhecimentos e habilidades pertinentes adquiridos e redes de atores em torno dos mesmos objetivos. Neste contexto, competência seria "um sistema de conhecimentos conceituais e procedimentais, organizados em esquemas operatórios e que permitem, dentro de uma família de situações, a identificação de uma tarefa-problema" (Gillet apud Boterf, 2003, p. 56). Desta forma, os atos do profissional competente devem ser "capazes de influenciar a resolução dos problemas a tratar ou a realização da atividade a executar: atos que fazem sentido" (Boterf, 2003, p. 40).

Semelhantemente, Perrenoud define a noção de competência "como sendo uma capacidade de agir eficazmente em um determinado tipo de situação, apoiada em conhecimentos, mas sem limitar-se a eles" (1999, p. 7). Vários recursos cognitivos complementares devem sem postos em ação, sinergicamente, para que seja possivel confrontar uma situação da melhor maneira possivel. Tal afirmação é compartilhada também por Boterf, haja vista ele declarar que a "competência do profissional está no saber combinatório [e as] ações competentes são o resultado disso" (2003, p. 12). Neste contexto, modos operatórios específicos, após serem aprendidos, formados e exercitados como ações voltadas a uma meta, podem entrar em ações mais complexas das quais se tornam meios. Tomemos como exemplo a competência da execução instrumental do pianista.

Entendendo-se execução instrumental como o canal condutor dos meios interpretativos, ela é, basicamente, "o resultado da conexão entre o conhecimento da teoria musical em seu amplo sentido e o domínio técnico instrumental inerente à realização da obra" (Póvoas, 1999, p. 2). Assim, a prática pianística é uma competência com certo nível de complexidade, devido à quantidade de domínios necessários, pois demanda que o corpo seja mobilizado para acionar o piano, que se ouça o resultado sonoro, analise-se este resultado e que se corrija a atuação sobre o instrumento. Tal prática pianística, para a função do pianista de coro, torna-se um meio para a realização das atribuições perante o coro. Neste caso, vê-se que "uma competência pode funcionar como um recurso, mobilizável por competências mais amplas" (Perrenoud, 1999, p. 28).

Muito embora dispor de amplos conhecimentos seja uma condição necessária de uma competência, ela "nunca é a implementação 'racional' pura e simples de conhecimentos, de modelos de ação, de procedimentos [...], pois a apropriação de numerosos conhecimentos não permite, ipso 
facto, sua mobilização em situações de ação" (Perrenoud, 1999, p. 8). Portanto, o profissional competente precisa não somente saber (e saberfazer), mas também utilizar tais domínios no momento oportuno, no kairos ${ }^{3}$. Assim, considerando que pode haver mais de uma forma de resolução de um problema, o julgamento de pertinência do que será mobilizado por parte do profissional faz parte de suas atribuições. É o caso dos especialistas, que possuem tanto a inteligência prática quanto a erudição do assunto, o que lhes permite desenvolver estratégias eficazes com rapidez e segurança maiores do que outras pessoas (Perrenoud, 1999, p. 9). Boterf complementa, defendendo que este profissional "sabe não apenas escolher, mas sabe escolher na urgência, na instabilidade e na efemeridade" (2003, p. 39). Ainda em consonância, ele também afirma que

[...] quanto mais um sujeito desenvolve seu nível de profissionalismo - e, portanto, quanto mais especialista se torna - menor será seu custo cognitivo, dispondo e executando esquemas operatórios que guiarão de modo econômico as combinações de recursos a realizar. Isso custará mais para o iniciante (Boterf, 2003, p. 53).

O caso do especialista é coerente com a função de pianista de coro, pois, tendo que resolver problemas como uma leitura à primeira vista ou deparando-se com um naipe dessincronizado com o grupo, sua experiência e conhecimento the permitem resolver as questões mais rapidamente do que outro pianista destreinado. Portanto, para que ocorra o desenvolvimento da experiência, há necessidade de contato com situações variadas. Assim sendo, é possivel inferir que um perito se forma por meio de vivências que podem ser ofertadas pelas instituições de ensino ou pela prática da profissão, considerando-se que a atuação do amador muitas vezes produz domínio em nivel especialista, e uma vez que "a aprendizagem acontece como um reflexo do treinamento, se este possibilitar a compreensão" (Figueiredo, 1990, p. 10). A formação dos esquemas do perito ocorre "ao sabor de um treinamento, de experiências renovadas, ao mesmo tempo redundantes e estruturantes, treinamento esse tanto mais eficaz quando associado a uma postura reflexiva" (Perrenoud, 1999, p. 10). As práticas competentes são baseadas em conhecimentos previamente adquiridos, e os conhecimentos tendem a ser incrementados na proporção que se avalia as situações já vividas, permitindo uma evolução constante da competência.

É preciso pensar "em termos de conexão, e não de disjunção, de parcelamento ou de fragmentação de ingredientes. Uma competência não pode ser apreendida ou compreendida ao termo de um recorte dos recursos que a constituem. A competência não está no final da dissecação" (Boterf,

\footnotetext{
${ }^{3}$ Kairos é filho de Chronos na mitologia grega, sendo o representante do momento oportuno, ao contrário do pai, que representa o fluir contínuo do tempo. $O$ termo "kairos possui uma dimensão temporal que indica um momento para agir" (Kjeldesn, 2014, p. 250, tradução nossa), sendo algo semelhante à "janela de oportunidade".
} 
2003, p. 56). Na Figura 1, a seguir, busca-se representar o conceito abordado. Vê-se como uma competência global tem competências especificas a serem mobilizadas judiciosamente, enquanto estas, por sua vez, possuem elementos formativos mais simples. $\mathrm{Na}$ figura em questão estão representadas duas competências específicas, a título ilustrativo, pois seu número é indefinido e depende de cada situação vivenciada. Da mesma forma, os elementos formativos das competências específicas são representações genéricas.

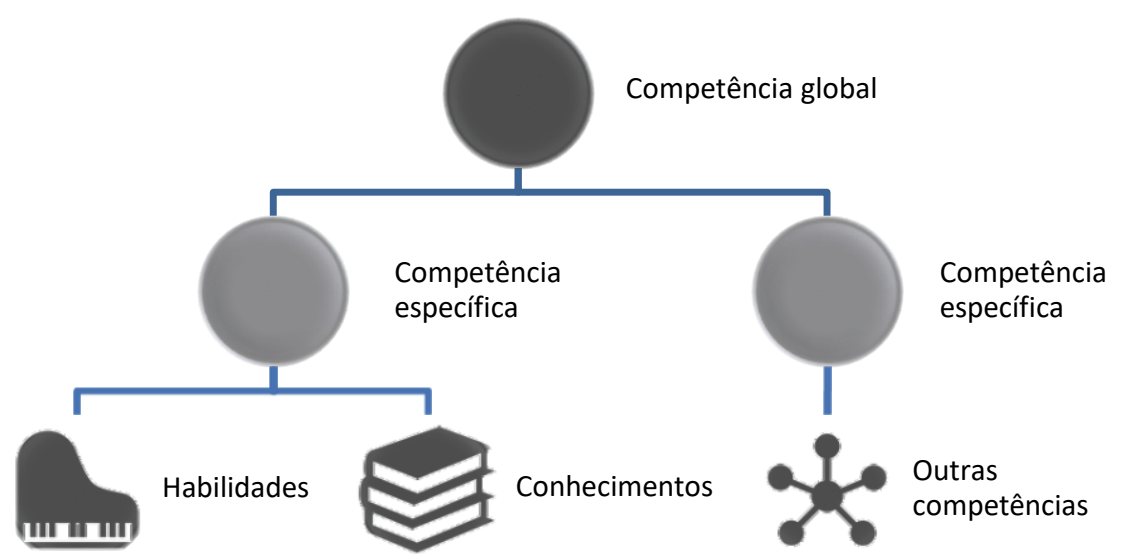

Figura 1: Representação dos elementos constituintes de competências (Friesen, 2018, p. 49).

Em sua pesquisa, Friesen (2018) averiguou que a competência global do pianista de coro no Brasil demanda a mobilização sensata de diversas competências específicas em níveis variados de intensidade, conforme representado na Figura 2. Na pesquisa não constam dados sobre elementos formativos das competências específicas (como domínio técnico-pianístico, teórico e artístico-musicais) e competências extramusicais (como competências sociais e postura profissional do pianista, por exemplo). Assim, entende-se que a competência global do pianista de coro é resultado da soma e mobilização judiciosa das competências específicas inerentes (Perrenoud, 2000, p. 16) apresentadas, como dominar leitura à primeira vista, realizar reduções de partituras em forma de "grade" etc., e estas, por sua vez, podem ser constituídas de outros elementos formativos fundamentais mais simples.

A competência global do pianista de coro no Brasil encontra-se representada na Figura 2, onde as proporções entre os círculos indicam as competências específicas e representam a intensidade de sua demanda. Dessa forma, Friesen (2018) levantou que os sujeitos pesquisados consideraram imprescindiveis: audição e execução polifônica, leitura à primeira vista e técnicas de ensaio. Foram consideradas muito necessárias: técnicas de regência, transposição, dicção de linguas estrangeiras e redução de grade. Por fim, baixo cifrado, técnicas de canto, criação de arranjos vocais e tocar "de ouvido" tendem a ser apenas razoavelmente necessárias. Esses 
dados são resultado de survey, onde cada um dos respondentes manifestou suas próprias experiências, que diferem, em maior ou menor grau, da tendência geral apresentada pelo autor.

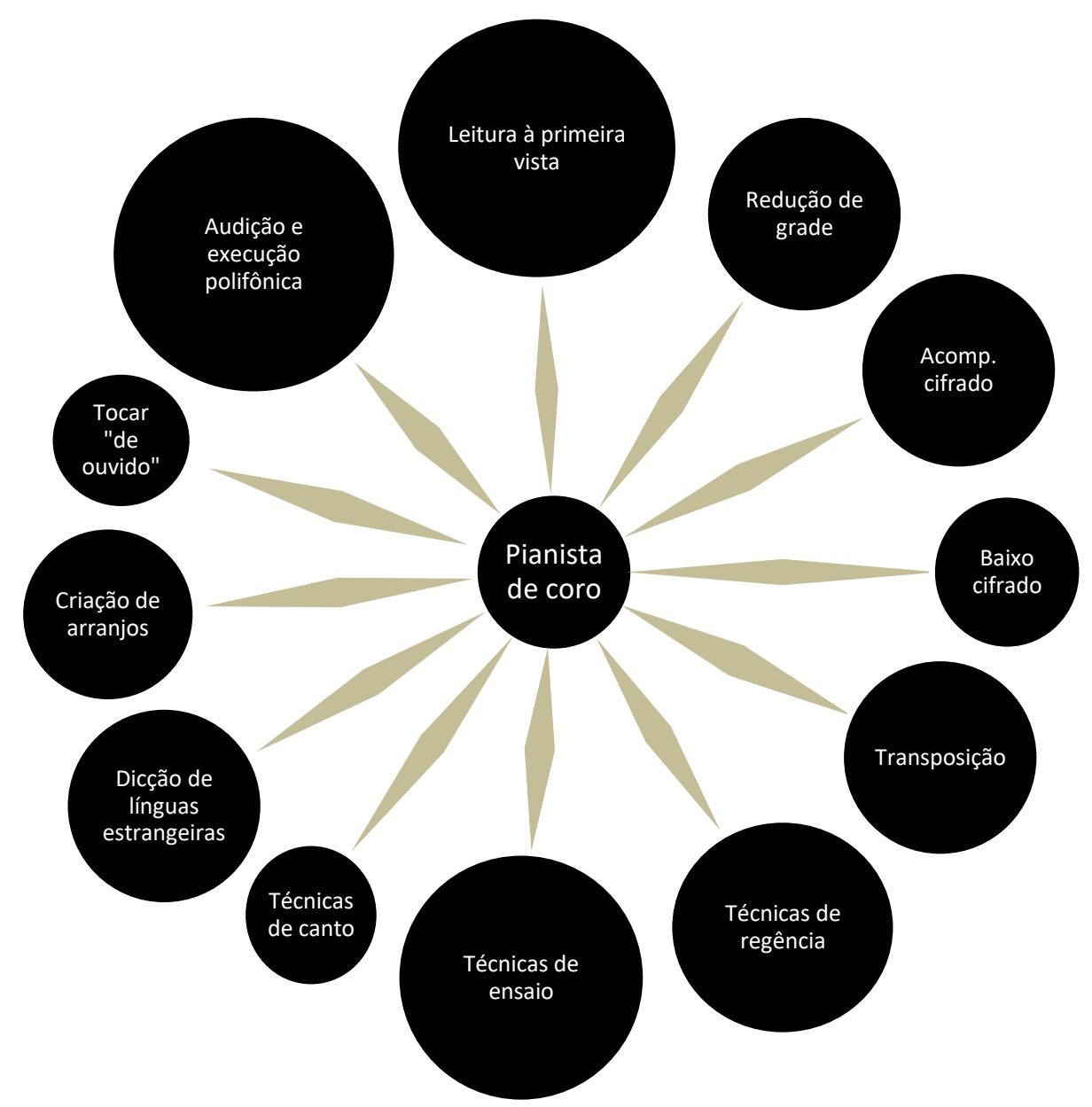

Figura 2: Representação da competência global do pianista de coro no Brasil (Friesen, 2018, p. 114).

Nas especialidades profissionais são requeridas inteligências específicas, próprias, devido à multiplicidade, quantidade e complexidade de eventos que surgem, situações essas que não podem ser dominadas exclusivamente através do senso comum (Perrenoud, 1999, p. 30). Para isso, é preciso ter "à sua disposição não só recursos específicos (procedimentos, esquemas, hipóteses, modelos, conceitos, informações, conhecimentos e métodos), mas também maneiras específicas e treinadas de mobilizá-los e colocá-los em sinergia" (Perrenoud, 1999, p. 30). Nesse contexto, o pianista de coro somente atuará de maneira competente se for capaz de usar os recursos que tiver disponiveis e forem cabiveis à função, como os apresentados na Figura 2.

A análise dos textos de Zarifian (2001), Perrenoud (1999, 2000) e Boterf (2003) mostrou semelhanças em suas abordagens do conceito de 
competências. Tal conceito está imbuído de uma natureza prática que não permite um mero saber, mas que demanda um saber-fazer. Também inclui a tomada de iniciativa por parte do sujeito competente, de forma que este assuma responsabilidade pela ação no momento adequado e, consequentemente, pelo produto final. Tais ações podem ocorrer frequentemente em situações inesperadas, o que pode produzir certo estresse que, espera-se, não domine o sujeito competente, pelo contrário, anseia-se que este profissional apresente a resolução do problema surgido.

Redes de atores mobilizadas em torno de objetivos comuns também constam no conceito de competência, levando-se em consideração que essas redes não incluem apenas outros indivíduos, mas também fontes de conhecimento, equipamentos ou outros meios que sirvam ao propósito comum. Tais atores carecem ser acionados quando o profissional não for capaz de, sozinho, resolver o problema surgido.

\section{CONSIDERAÇÕES FINAIS}

O presente artigo objetivou apresentar uma discussão sobre o conceito de competência e mostrar formas de sua aplicação à atuação de pianistas de coro, segundo levantamento das competências, global e específicas, realizado por Friesen (2018) em um survey com pianistas e regentes atuantes em coros no Brasil. Sabe-se que podem ocorrer variações em estudos de caso que avaliem situações e especificidades de atuação, isoladamente, como é o caso da pesquisa de Filho (2019).

Entende-se que o conceito de competência, com suas ramificações, é aplicável à função do pianista de coro, conforme buscou-se pautar no decorrer do texto. Outras atividades também poderiam se apropriar de tal conceito, aplicando-o às mais variadas áreas de atuação, além da própria prática pianística. Nesta prática, para executar o instrumento, o indivíduo precisa acioná-lo tradicionalmente com seu corpo, mas uma ação pianística otimizada demanda a mobilização de competências ou outros conhecimentos, como exposto por Póvoas (1999). Assim, poderia ser pesquisada a correlação entre otimização e as competências necessárias para tal atividade. Ao indivíduo que pretende atuar na área da colaboração pianística junto a coros, seria recomendável aprofundar-se no conhecimento de quais competências específicas constituem sua competência global, com o objetivo de melhor preparar-se para o desempenho da função.

Considerando-se que a atuação competente consiste em resolver as situações planejadas e também os imprevistos que surgirem, a formação do pianista de coro poderia ser voltada tanto para o enfrentamento de tais eventos, através do domínio das diversas competências específicas, como de treinamento, para que ocorra a sua mobilização judiciosa. Cabe salientar que as Diretrizes Curriculares Nacionais dos Cursos de Graduação em Música definem em seu artigo $3^{\circ}$ que tais cursos devem revelar "habilidades 
e aptidões indispensáveis à atuação profissional na sociedade" (Brasil, 2004, s.p.) e que devem haver "estudos que permitam a integração teoria/prática relacionada com o exercício da arte musical e do desempenho profissional" (Brasil, 2004, s.p.).

Presume-se que as informações e os dados aqui apresentados oportunamente poderão ser apropriados por instituições de ensino de música, mais especificamente aquelas que formam pianistas e regentes, para incluir a preparação da colaboração pianística junto a coros para o mercado de trabalho em seus processos formativos. Cabe ainda ressaltar que, se a qualificação for reduzida a diplomas de formação inicial, "isso não significa que a pessoa saiba agir com competência. Significa, antes, que ela dispõe de certos recursos com os quais pode construir competências" (Boterf, 2003, p. 21). Dessa forma, tem-se que a formação de pianistas colaboradores precisa passar por todos os níveis formativos, desde o básico até o superior.

\section{REFERENCIAS}

BOTERF, Guy Le. Desenvolvendo a competência dos profissionais. Tradução Patrícia Chittoni Ramos Reuillard. 3. ed. Porto Alegre: Artmed, 2003.

BRASIL. Conselho Nacional de Educação. Resolução $n^{\circ}$ 2, de 8 de março de 2004. Aprova as Diretrizes Curriculares Nacionais do Curso de Graduação em Música e dá outras providências. Diário Oficial da União, Brasília, 12 de março de 2004, seção 1, p. 10.

CIANBRONI, Samuel Henrique da Silva. Perspectivas e impasses na mobilização de conhecimentos em música de graduandos em situações de colaboração pianística: estudos exploratórios. 2016. 124 f. Dissertação (Mestrado em Música) - Universidade Federal do Rio Grande do Sul, Porto Alegre, 2016.

FIGUEIREDO, Sergio Luiz Ferreira de. O ensaio coral como momento de aprendizagem: a prática coral numa perspectiva de educação musical. 1990. 144 f. Dissertação (Mestrado em Música). Universidade Federal do Rio Grande do Sul, Porto Alegre, 1990.

FILHO, Luiz Andrade de Souza. A colaboração pianística no coro da Igreja Batista Regular de Boa Vista: competências exercidas no dia a dia. 2019. 59 f. Monografia (Graduação em Música) - Universidade Federal de Roraima, Boa Vista, 2019.

FRIESEN, Rafael Ricardo. Panorama das competências do pianista de coro no Brasil. 2018. 170 f. Dissertação (Mestrado em Música) - Universidade do Estado de Santa Catarina, Florianópolis, 2018. 
KJELDESN, Jens. Reconceptualizing kairos. In: Papers and monographs from the norwegian institute at Athens, Atenas, 4ª série, v. 2, p. 249-258, 2014. Disponivel em

https: / /www.academia.edu/9777814/Reconceptualizing_kairos. Acesso em: 16 out. 2017.

PAIVA, Sérgio. O pianista correpetidor na atividade coral: preparação, ensaio e performance. 2008. $65 \mathrm{f}$. Trabalho de produção artística e artigo (Mestrado em Música) - Universidade Federal de Goiás, Goiânia, 2008.

PERRENOUD, Philippe. 10 novas competências para ensinar. Tradução Patrícia Chittoni Ramos. Porto Alegre: ArtMed, 2000.

PERRENOUD, Philippe. Construir as competências desde a escola. Tradução Bruno Charles Magne. Porto Alegre: ArtMed, 1999.

PÓVOAS, Maria Bernardete Castelán. Controle do movimento com base em um principio de relação e regulação do impulso mecânico: possiveis reflexos na otimização da ação pianística. 1999. 259 f. Tese (Doutorado em Música) Universidade Federal do Rio Grande do Sul, Porto Alegre, 1999.

ROSA, Alexandre Reis. Um século de taylorismo. GV Executivo, v. 10, n. 2, p. 22-25, jul./dez. 2011. Disponivel em:

https://www.academia.edu/7557002/Um_s\%C3\%A9culo_de_Taylorismo.

Acesso em: 16 out. 2017.

ZARIFIAN, Philippe. Objetivo competência. São Paulo: Editora Atlas, 2001. 
Rafael Ricardo Friesen é Bacharel em Piano e Especialista em Performance - Música de Câmara pela Escola de Música e Belas Artes do Paraná, Mestre pela Universidade do Estado de Santa Catarina na área de Interpretação e Criação Musical. Premiado em concursos nacionais de piano. Atuou em diversos concertos como solista, recitalista e camerista, com especial ênfase em música contemporânea. Professor e coordenador do curso de Licenciatura em Música da Universidade Federal de Roraima. https://orcid.org/0000-0002$\underline{2751-5210}$

Maria Bernardete Castelan Póvoas é Graduada na modalidade Instrumento Piano, tem mestrado e doutorado em música, Práticas Interpretativas, pela Universidade Federal do Rio Grande do Sul (UFRGS). Em 2018/19 realizou estágio pós-doutoral no Instituto de Etnomusicologia, Centro de Estudos em Música e Dança (INET-md), pólo da Universidade de Aveiro (DeCA-UA), sob a supervisão da Profa. Doutora Helena Marinho. É professora associada na Universidade do Estado de Santa Catarina (UDESC) onde atua nos cursos de Bacharelado e Pós-Graduação em atividades de ensino, extensão e pesquisa interdisciplinar sobre desempenho pianístico e música de câmara. É líder do Grupo de Pesquisa Processos Músico-Instrumentais, PROMUSI, (CNPq/UDESC). Tem publicações nas revistas da ABEM, DaPesquisa, Em Pauta, Opus, Revista Eletrônica de Musicologia e Vórtex. Realiza recitais solo e de câmara em diferentes formações, estreias e gravação de CD. Integra o Duo de piano Castelan \& Barros desde 2010 com turnês e participações em eventos artísticos e científicos no Brasil e exterior. http://orcid.org/0000-0002-3169-4215 